\title{
Relato sobre a experiência do comitê Marielle Franco de Toulouse
}

Raisa Inocencio Ferreira LIMA, Universidade de Toulouse

Ensaio que procura resumir as ações e o percurso do comitê Marielle Franco de Toulouse, como também um testemunho pessoal e afetivo, a proposta do ensaio é trazer à luz um modo de organizar eventos que congregam a ajuda aos movimentos sociais no Brasil, desde uma luta no exilio e imigração na Europa. Portanto, sendo uma conversa de intensidades e coragem, tendo em vista uma poética da vida, não somente uma política.

PALAVRAS-ChaVE: Marielle Franco. Toulouse. França. 


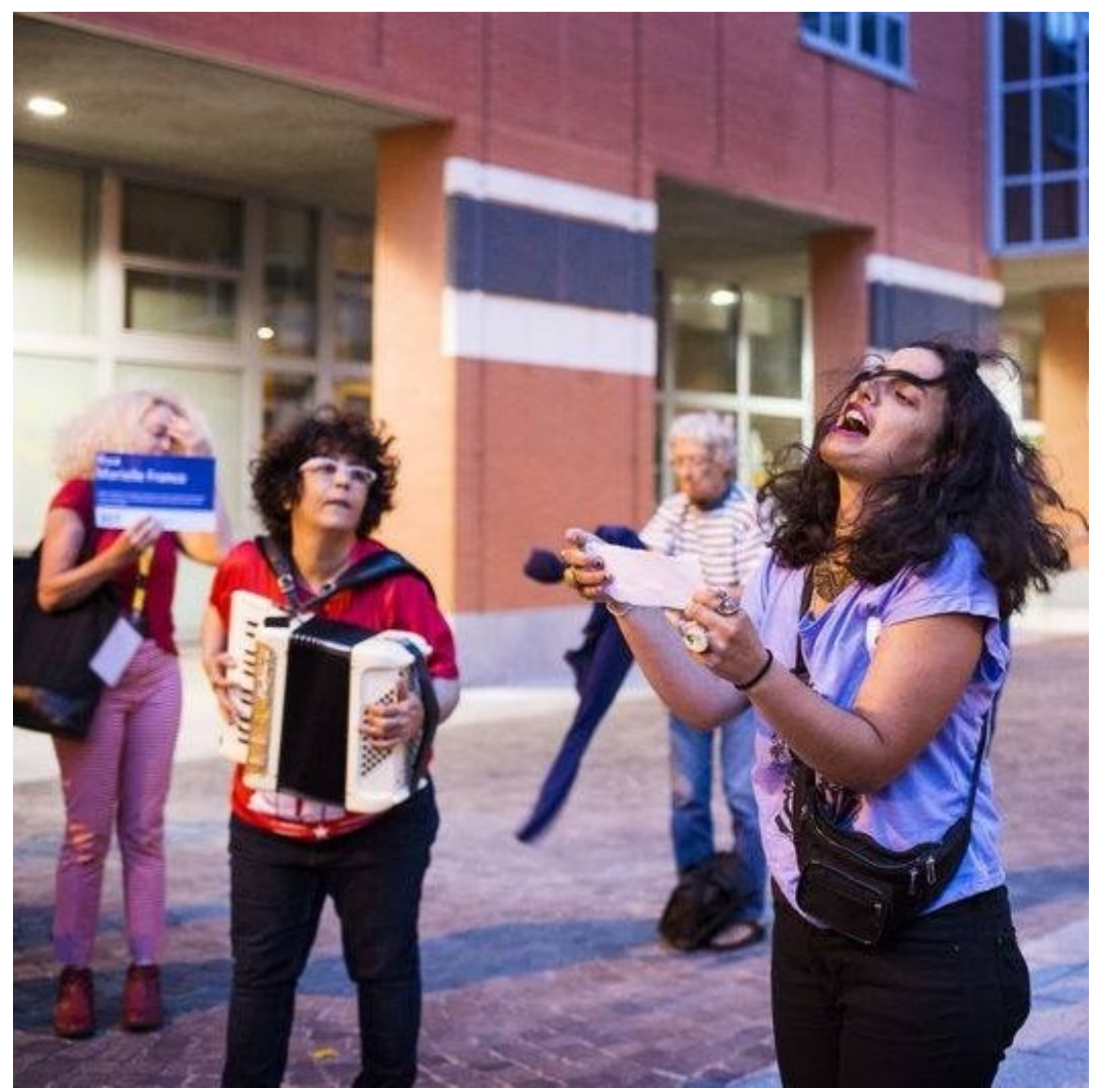

Fig. 1 Performance de Raisa Inocêncio, Virginie B. e Rita Macedo. Noite de homenagem à Marielle Franco. Conselho departamental de Haute Garrone. Junho, 2019. Foto anônima.

Este ensaio procura apresentar a ação do comité Marielle Franco, localizado em Toulouse (França), que conta com o apoio de diferentes redes e coletivos dedicados, em primeiro lugar, a prestar homenagem à vida e ao trabalho político da vereadora Marielle Franco. Tendo dois objetivos centrais, o primeiro, que é traduzir e dar visibilidade a própria pessoa da Marielle como também a situação atual do Brasil, através de participação em eventos e na publicação de textos; o segundo objetivo é a organização de festas de apoio aos projetos em marcha no atual contexto brasileiro, de movimentos sociais e iniciativas individuais. 
O assassinato de Marielle, que foi morta em 14 de Março de 2018 no final de um evento intitulado "Juventude Negra em Luta!", provoca até hoje a indignação, pois a sua morte é profundamente injusta. Embora não saibamos quem a matou, podemos suspeitar que a sua luta contra a corrupção e a violência policial terá sido fatal para ela. Sem notícias até agora de quem ordenou o seu assassinato, é concebível que a sua execução tenha sido realizada por forças paramilitares e armadas.

Marielle Franco é atualmente um símbolo de luta, apesar de toda a propaganda que visa desmobilizar os seus apoiantes e reduzir o seu assassinato e o do seu motorista a uma mera estatística. Essa força reapareceu em manifestações públicas no Brasil e em outros lugares, revelando um verdadeiro sopro de solidariedade e resistência.

Como podemos reagir a esta cultura de violência e medo, cujas raízes se baseiam historicamente numa economia colonial e escrava, que ainda nos inflige um modo de sobrevivência e de exílio?

Nós brasileiros, exilados e emigrados na Europa, estamos reagindo à situação catastrófica resultante da chegada do governo Bolsonaro, e suas ações mais propicias à un diagnostico de necropolítico, o que implica em termos de um verdadeiro genocídio uma ação conjunta e estratégica. Portanto, como devemos operar em termos de estratégia de reflexão e reação? E a segunda pergunta é: como nos organizamos diante desta constante perseguição?

Este conflito cada vez mais real dá-nos, enquanto comitê Marielle Franco, uma primeira motivação para tornar visíveis e denunciar os ataques contra a humanidade levados a cabo pelo governo Bolsonaro. É uma luta entre, por um lado, um grupo muito poderoso que defende abertamente o genocídio contra a população afro-indígena, LGBTQI+ e outras minorias como também da destruição do clima, com um desflorestamento recorde. Por outro lado, sabemos que é uma rede de resistência que não tem grandes recursos de mídia, e que, por isso, opera em uma escala menor e, no entanto, igualmente significativa.

O comitê Marielle Franco toma, como força motriz principal, estas questões e motivações como um primeiro eixo, o da visibilidade e tradução de textos e artigos, para relatar a situação desde o que ocorre no Brasil. Posteriormente, através da participação em todo o tipo de eventos, festivais ou reuniões, desejamos também estabelecer uma visibilidade e articulação social destas questões. 
Nosso segundo eixo é o apoio a projetos de defesa dos movimentos sociais, atualmente apoiando em duas ações, centrados no Nordeste do Brasil: a primeira, em parceria com a rede Technoxamanismo ${ }^{1}$ e a associação do povo Pataxón ${ }^{2}$, um projeto que visa construir um posto de saúde e uma casa de cura, junto a prática médica a combinação de conhecimentos indígenas com permacultura, agrofloresta e ecologia social; o segundo é o apoio ao MST3 (Movimento dos Sem Terra), que abrange em sua totalidade não só as questões afro-indígenas, feministas, mas também a ecologia, o respeito à terra e a produção orgânica de seus produtos.

\section{Origem}

Foi através da associação FAL (França América Latina) que recebi o convite para organizar um comitê de solidariedade brasileira em homenagem a Marielle Franco. Fui a algumas reuniões e na minha opinião foi uma experiência fundamental para entender os interesses ativistas: o funcionamento, a participação e a mobilização social em torno da situação atual na América Latina e os interesses políticos desde a eleição do governo Bolsonaro.

Sobre a associação FAL, é uma associação que existe há 50 anos e que ajuda ativamente os ativistas latino-americanos diante dos golpes militares, perseguição e desaparecimento de ativistas e da recepção de exilados latino-americanos.

Nas palavras do site oficial da associação, a FAL pode ser resumida da seguinte forma4:

Desde 1970, a França América Latina trabalha para dar a conhecer a história, as culturas nativas e mistas, as mobilizações e demandas dos povos da América Latina e do Caribe em toda a sua diversidade. Mostramos nossa solidariedade com eles, divulgando informações sobre suas experiências coletivas, aprendendo com suas lutas e

1 Site da rede de arte e ativismo do Tecnoxamanismo: https:// tecnoxamanismo.wordpress.com/

2 Ponto de cultura Pataxó da Aldeia Pará: https://permaculturapataxo.wixsite.com/ permacultura

3 Movimento Sem Terra, site : https://mst.org.br/

4 Sobre a associação (em francês) : https://www.franceameriquelatine.org/qui-sommesnous/ 
apoiando suas lutas contra a impunidade, pelo respeito aos direitos humanos, pela democracia política, pelo progresso social e bem-estar, bem como pela proteção do meio ambiente e da mãe terra.

A associação é composta por cerca de trinta comissões locais representando várias centenas de membros em todo o país e decide autonomamente sobre as suas acções prioritárias de acordo com as orientações nacionais, discutidas e votadas na Assembleia Geral. A ação da FAL está de acordo com as exigências do movimento antiglobalização e dos movimentos sociais internacionais. Assim, a FAL trabalha com ONGs, associações, sindicatos, movimentos sociais em França, na Europa e na América Latina. Nossa associação é membro entre outros - do Comitê de Pesquisa e Informação sobre o Desenvolvimento (CRID), do Coletivo Guatemala, do Coletivo Haiti da França... A associação realiza trabalhos de reflexão e informação sobre parceria econômica e acordos de livre comércio, assim como sobre o papel das multinacionais, através de debates, petições cidadãs, manifestações e intervenções diretas com autoridades nacionais e internacionais.

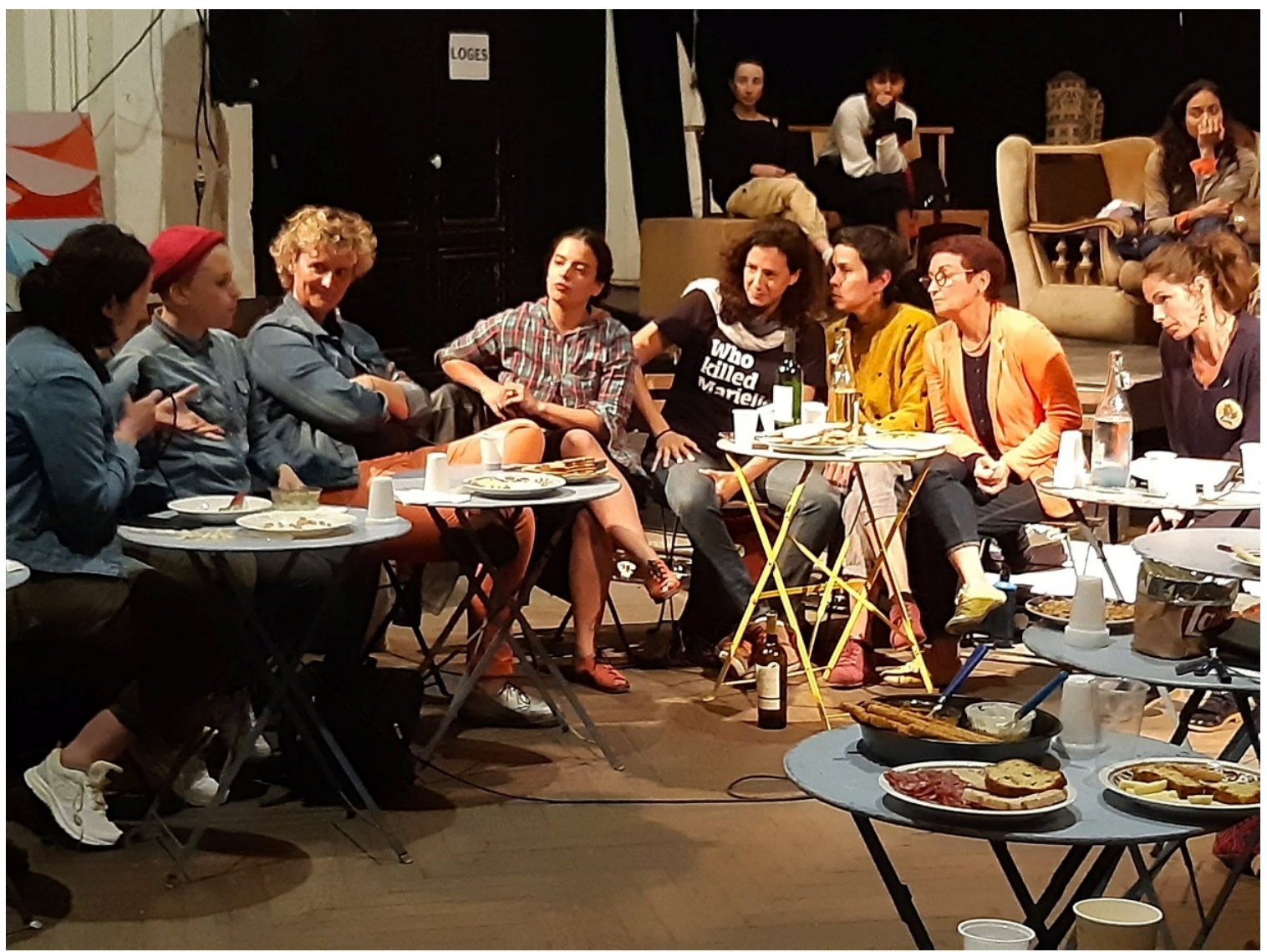

Fig. 2 Café feminista com Monica Benicio. Junho 2019. La Chapelle. Foto anônima. 


\section{Ações - percursos}

O primeiro evento foi realizado em janeiro de 2019, na comuna de Tarnac, na região do Plateau de Millevaches, região conhecida por suas iniciativas politizadas e militantes. Organizar esse primeiro encontro, foi especialmente um laboratório, pois me sentia "em casa" ao mesmo tempo que é um espaço comum. Houve um debate que cada convidado pôde dar sua perspectiva, também tendo perguntas como: quais são os protocolos e mecanismos a serem implementados na organização de eventos cujo interesse (e razão) mostram em outro lugar a questão da luta no Brasil?

Então, este laboratório contou com a rede militante do Plateau de Millevaches, como uma ferramenta de escuta para compreender quais são os alicerces que sustentam um movimento em luta. O evento também teve lugar em Eymoutiers com uma conferência de Oiara Bonilla e a apresentação da revista "Africultures" por Dénètem Touam Bona5.

Segue citação do resumo publicado no site da Médiapart sobre a organização deste evento ${ }^{6}$ :

Nos dias 15 e 16 de Janeiro, a Magasin général de Tarnac e a Montagne Accueil Solidarité vão oferecer-lhe duas oportunidades para discutir a situação no Brasil, onde a chegada ao poder de Jair Bolsonaro reforça a espiral de regressão política, social e ambiental iniciada pelo golpe de Estado institucional de 2016.

Além da reabilitação da ditadura militar e da ordem moral cristã (estabelecimento do criacionismo no ensino e demonização do feminismo e movimentos LGBTQI+), o que também se anuncia é o reforço do terror nas favelas (7 vezes mais negros mortos no Brasil do que nos EUA) e a devastação radical do ambiente de vida. Há urgência porque o ecocídio (a destruição do meio ambiente) - ligado à predação de interesses mineiros e agro-industriais - não pode ser dissociado da perpetuação do etnocídio das comunidades "afro-indígenas" (negros e ameríndios, com seus diversos graus de "hibridização").

Vários testemunhos e análises políticas irão lançar luz sobre a sequência que levou Jair Bolsorano ao poder. Esta noite também será

5 Sobre Dénètem Touam Bona (em francês) : https://www.multitudes.net/author/denetemtouam-bona/

6 Médiapart : https://blogs.mediapart.fr/denetem/blog/o90119/devenir-fasciste-etresistances-creatrices-au-bresil 
uma oportunidade para entender o papel decisivo que os movimentos LGBTQI+, feministas e artísticos sociais terão que desempenhar, o ativismo nas áreas rurais levado pelo movimento sem-terra, e para abordar a idéia de "política indígena". Diretamente ameaçado, este "menor" Brasil ou este "alter-Brasil" está por necessidade no coração da organização da resistência a este novo regime que se define como racista, homofóbico, misógino, defensor da tortura e incentivador, na violência, da destruição da Amazônia...

Esta discussão foi realizada com quatro convidados, cada um falando sobre um tema diferente: eu, que iniciei o debate sobre o comitê Marielle Franco, Fabio Queiroz, historiador e ativista LGBTQI+, Flora Mangini, representante do coletivo feminista Marielles, e Julien Pallotta, professor de filosofia no Rio de Janeiro e tradutor de Eduardo Viveiros de Castro. A discussão também foi acompanhada por uma refeição de especialidades brasileiras e pelo filme "Terra em transe" de Glauber Rocha (1967).

Depois, com base nesta primeira experiência, formalizamos em Toulouse a mobilização das pessoas empenhadas em participar do comitê e assim organizar uma noite para o lançamento do comitê Marielle Franco7. Foram, em uma noite, 14 voluntários, dois concertos, uma mesa redonda. Também servimos feijoada para 350 pessoas e cerca de 500 pessoas vieram ao evento que teve lugar no La Chapelle, uma antiga ocupação conhecido pela sua abertura a projetos engajados. Foi admirável que em tão curto espaço de tempo tenhamos conseguido uma mobilização desta altura.

Também, naquela noite, houve um encontro com outras redes que também fazem manifestações públicas, nomeadamente a Red.Br e a Fiertés Occitanie. A partir desse dia, toda uma agenda de participação em eventos e a publicação de artigos e links começou, especialmente, a presença de Monica Benício em algumas ocasiões em Toulouse. Primeiramente, em junho, como madrinha na parada do Orgulho LGBT de 2019, em seguida, numa noite dedicada à memória de Marielle Franco no Conselho departamental de Haute-Garonne ${ }^{8}$.

7 Relato : https://tecnoxamanismo.wordpress.com/2019/o3/27/tecnoxamanismo-no-lachapelle-toulouse-franca/

8 Publicação no site oficial do departamento de Haute Garonne : https://www.hautegaronne.fr/inscription-soiree-hommage-marielle-franco 
Em novembro, Monica retornou à Toulouse, para a participação em dois eventos, primeiro no Seminário Pensar as descolonizações ${ }^{9}$, da Universidade de Toulouse, organizado pelo laboratório ERRAPHIS (Equipe de pesquisa sobre as racionalidades filosóficas e os saberes) e no Festival LatinoDocs seguido de debate ${ }^{10}$.

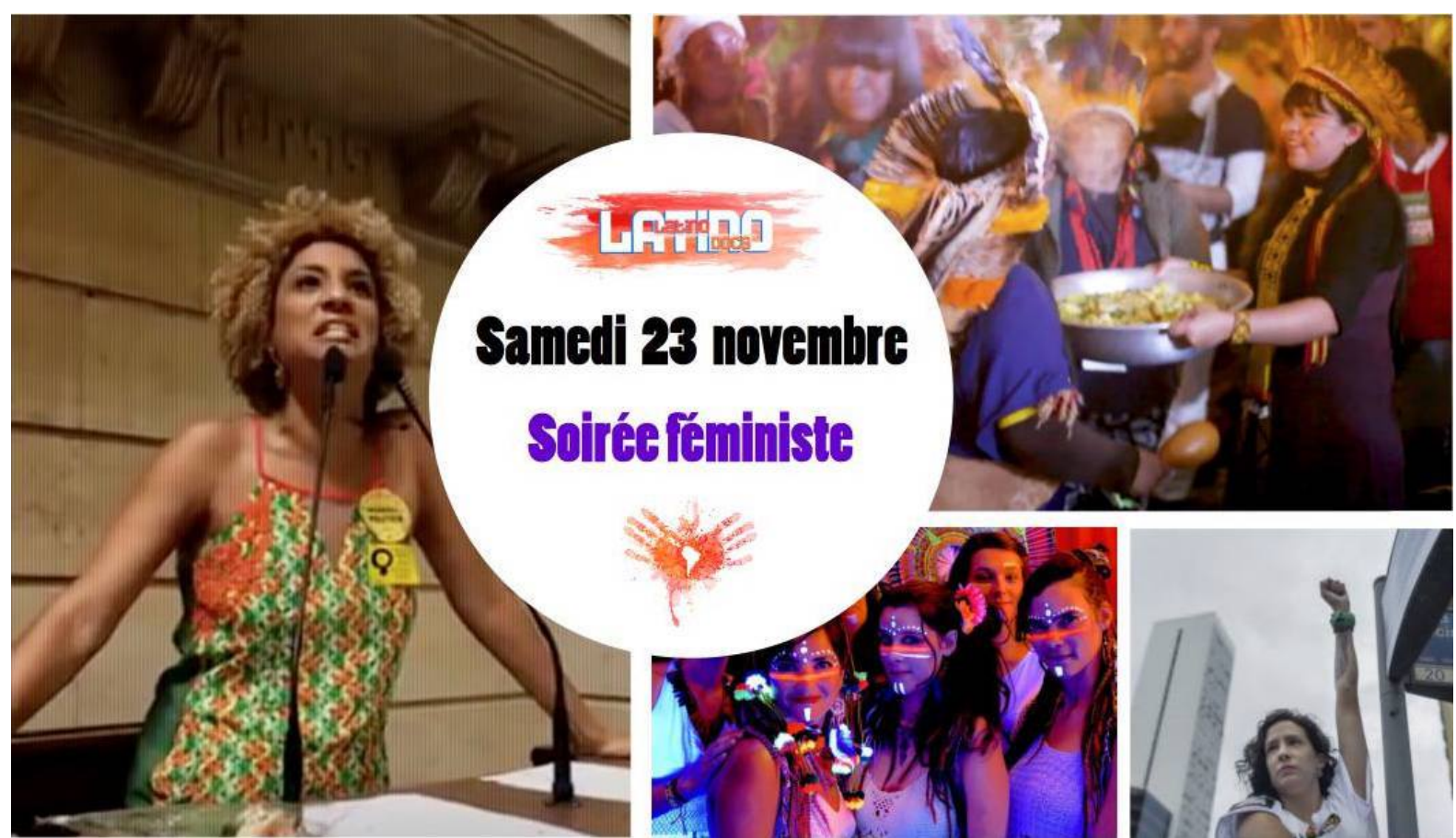

Fig. 3 Cartaz do evento "Noite feminista" do Festival Latino-Docs 2019.

Participei de outros eventos, nos quais discutimos temas ligados à transversalidade da luta e a necessidade de pensar que as opressões são interseccionais, no sentido de que operam em uma dinâmica em várias frentes. Ressaltamos a apresentação dos livros "Lugar de Fala" e "Quem tem medo do Feminismo Negro" de Djamila Ribeiro ${ }^{11}$.

A entrevista feita para a revista Africultures ${ }^{12}$ e a organização de duas festas e uma mesa redonda em Paris e Toulouse.

9 Seminário Pensar as descolonizações : https://europhilomem.hypotheses.org/7831 ; nota sobre o evento de apoio à universida brasileira : https://europhilomem.hypotheses.org/7810

10 Festival Latino-Docs : https://latino-docs.org/index.php/le-festival/

11 Site da editora em francês : https://www.anacaona.fr/djamila-ribeiro-afro-feministefeminisme-noir/

12 Entrevista com Africultures sobre o comité Marielle Franco : http://africultures.com/ marielle-franco-a-re-signifie-la-politique-contemporaine-bresilienne/ 


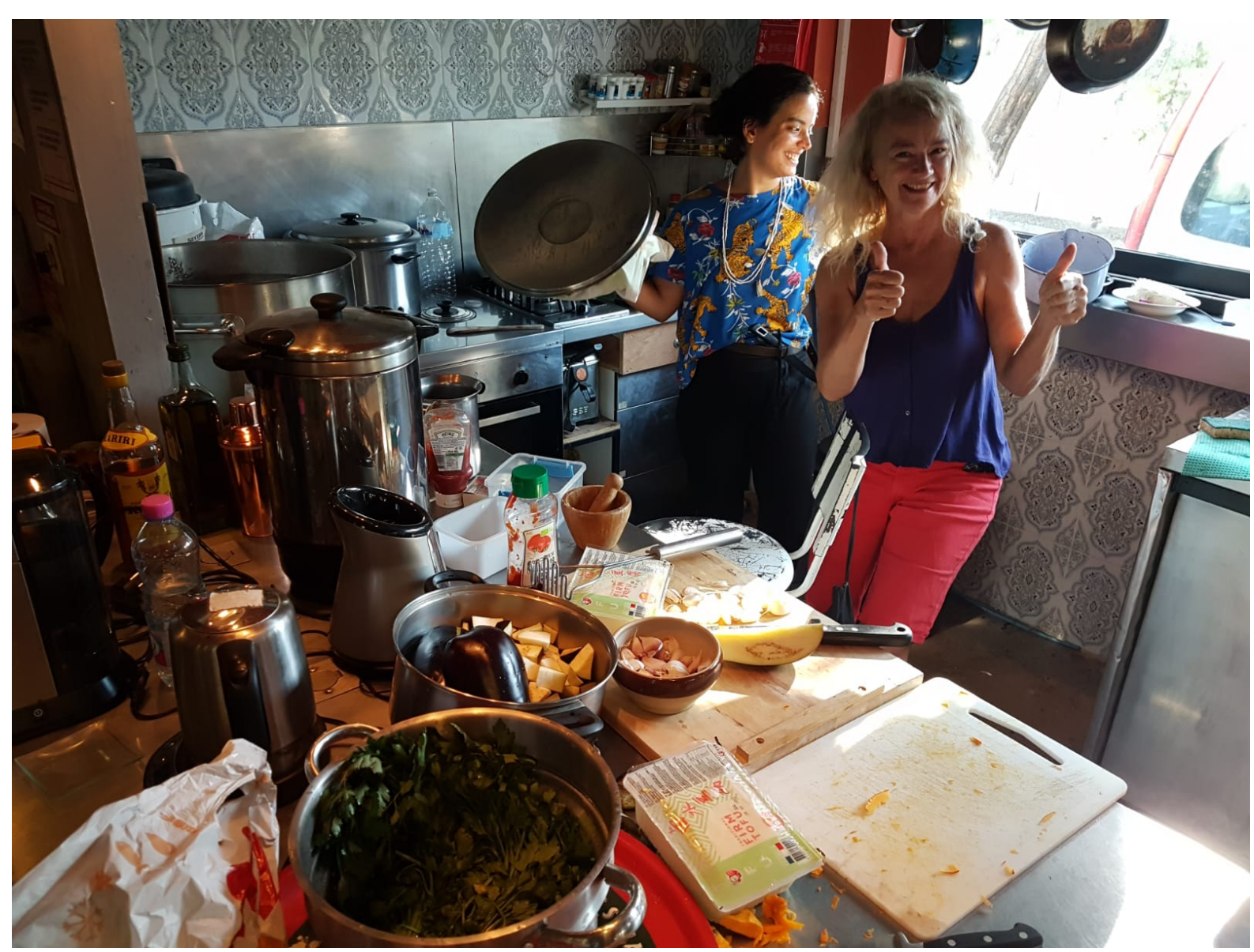

Fig. 4 Feijoada no Hangar. Toulouse, setembro 2019. Foto : Alexandre Ruoso.

Finalmente, como comitê de Marielle Franco, eu participei como tradutora, pontualmente, no comitê internacional "Lula Livre"13 e em outras iniciativas informais de auxílio administrativo e acadêmico.

Fora das ações do comitê pontuamos que este ano um grande evento ocorreu em homenagem à Marielle Franco, contando com a sua família, que foi a inauguração do jardim Marielle Franco, à Paris. A inauguração, organizada pela Red.Br ${ }^{14}$ em parceria com a prefeitura de Paris, com apoio de outras organizações como o Autres Brésils e o coletiva Marielles, ocorreu no dia 21 de setembro, o que expõe a

13 Alguns links de traduções feitas : https://www.comitelulalivre.com/fr/mafieux/ ; https:// www.comitelulalivre.com/fr/au-mexique-le-collectif-regina-de-sena-mexique-bresil-contrele-coup-detat-proteste-pour-lulalibre/ ; https://comitelulalivre.org/fr/le-comite-parisienparticipe-a-lacte-contre-la-persecution-des-dirigeants-de-mouvements-sociaux-et-pourlulalibre/ ; https://comitelulalivre.org/fr/le-candidat-a-la-presidentielle-argentine-albertofernandez-rend-visite-a-lula/

14 Site do Red.Br : https://red-br.com/marielle-franco-a-paris/ 
pertinência da figura política e o desejo de continuar a difundir seu trabalhos como também seus combates.

Análogo em relação à sua percepção das organizações e lutas, o comitê também se concentra no trabalho acadêmico em apoio, em particular, aos professores que estão atualmente sob ameaça. Neste semestre de setembro a dezembro de 2019 houve conferências de filósofos e intelectuais brasileiros como Viveiros de Castro, Deborah Danowski, Vladimir Safatle, Marcia Tiburi, e outros como Cecilia Cavalieri, como dito anteriormente, Djamila Ribeiro e a presença excepcional de Monica Benício, que teve apoio de Stéphanie Palancade, o que ainda nos deixa motivados a continuar a mobilização de convocatória, resistência e visibilidade em memória de Marielle Franco, por uma política mais solidária e de direitos humanos.

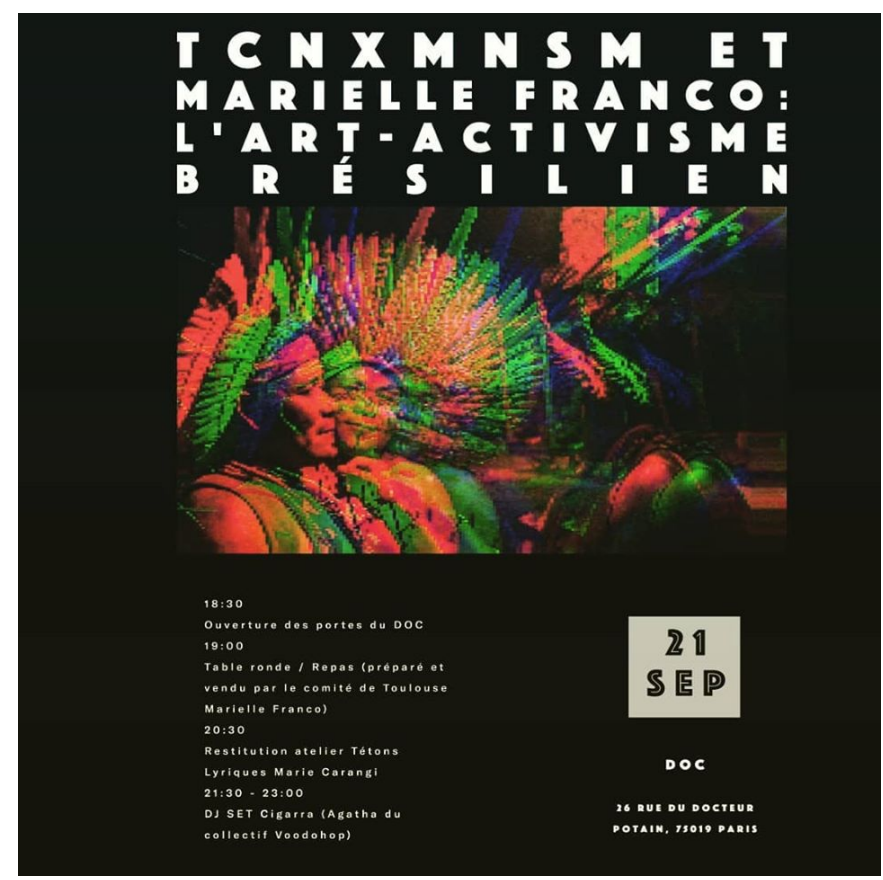

Fig.5 Cartaz do evento "Arte e ativismo brasileiro" no espaço cultural DOC, Paris, setembro, 2019.

\section{Anúncio do edital da Região Occitanie pra saúde Pataxó}

Por meio de edital da região Occitanie, foi aprovado em julho deste ano, o projeto de saúde Pataxó, o qual possui subvenção de treze mil euros para a construção de um posto de saúde, de casa de cura e da 
manutenção dos projetos já existentes de agrofloresta e permacultura. Durará três anos no sul da Bahia, em parceria com a rede Tecnoxamanismo, contando com o chamado para o Mutirão da construção coletiva do Posto de Saúde Pataxó, a ser realizada dos dias 20 a 25 maio de 2020. Como indica o texto que convoca à participação do Mutirão15:

Para conseguir os recursos materiais para a construção dos POSTOS DE SAÚDE foi feito um crowdfunding no Catarse e alguns encontros da rede de tecnoxamanismo em São Paulo, Berlim, Paris e Londres, que através das doações de colaboradores atingiu seu objetivo de levantar 30 mil reais. Para a implementação do projeto, teve um edital aprovado pela região Occitanie em parceria com a associação FrançaAmérica Latina (FAL) e o comitê Marielle Franco de Toulouse, localizado no sul da França, tendo um orçamento previsto de 13 mil euros com duração de três anos. O projeto conta também com a manutenção das iniciativas agroflorestais e de recuperação de nascente de rios, o que servirá como um apoio à autonomia alimentar e o funcionamento dos POSTOS DE SAÚDE.

MUTIRÃO é uma das formas mais potentes de colaboração porque cria mobilização coletiva, produz ajuda mútua, promove independência e emancipação dos povos. Participar de um MUTIRÃO é uma oportunidade única de transformação da realidade que traz muitos benefícios para aprendizagem e desenvolvimento humano. Em momentos de catástrofes climáticas e humanas como as que estamos vivendo hoje em dia, é fundamental apoiar projetos autônomos, de empoderamento de minorias, de justiça social.

São muitos fatores que se somam quando se fala em SAÚDE INDÍGENA. Vai desde o cuidado com a água, com o solo, com o saneamento básico, com alimentação, com assistência preventiva, assistência social, até fatores relacionados à mortalidade infantil, epidemias, doenças respiratórias, diarréicas, doenças imunopreveníveis, malária e tuberculose, cardiopatia, doenças hemofílicas, doenças renais, câncer entre outros.

A criação de dois postos de saúde, um tradicional indígena e outro ambulatorial traz como desafio a intersecção de campos de conhecimentos, de forma a criar interdependência e complementaridade entre os saberes tecnológicos e xamânicos, entre a cultura do médico e a cultura das curandeiras, das mães, das parteiras. Isso é um desafio e uma necessidade em todo o continente sul americano, assim como em todo o mundo. Operar com conhecimentos

15 Texto completo e formulário de inscrição : https://tecnoxamanismo.wordpress.com/) 
atuais e ancestrais é um grande desafio mas também um grande sonho.

Tal aprovação nos deu os meios de assegurar o orçamento e os recursos necessários para uma efetiva resistência e contribuição, por exemplo, à saúde indígena. Sabemos, no entanto, de uma escala micropolítica, não diminuindo assim o significado que este Centro de Saúde Pataxó nos dará, visto que ocorre um verdadeiro desmonte na saúde indígena, tomando mais uma vez como citação um trecho do texto do Mutirão ${ }^{16}$ :

O desmonte das políticas da saúde indígena manifesto na perda de autonomia de programas como a SESAI (Secretaria Especial de Saúde Indígena), DSEI (Distrito Sanitário Especial Indígena), o fim do Programa Mais Médicos, o esvaziamento de unidades gestoras de saúde, o descaso com as Casas de Saúde Indígena (local onde os doentes ficam em tratamento ou aguardam para serem atendidos nos hospitais para questões de saúde mais complexas), as mudanças estruturais que o SUS vem passando ou a reestruturação da FUNAI (Fundação Nacional do Índio), a precariedade de infraestrutura e de recursos logísticos para atendimento aos indígenas têm preocupado os povos indígenas, que desde o início de 2019 tem feito várias manifestações no Ministério da Saúde, se opondo a decretos como o da municipalização da Saúde Indígena ou da recente Portaria 13.623 feita pelo governo federal que ordena a centralização dos processos e contratações públicas pelos órgãos federais.

Um dos princípios da Saúde Indígena declarada na III Conferência Nacional de Saúde Indígena, realizada em 2001 diz que: “... cada povo indígena tem suas próprias concepções, valores e formas próprias de vivenciar a saúde e a doença. As ações de prevenções, promoções, proteção e recuperação da saúde devem considerar esses aspectos, ressaltando os contextos e o impacto da relação de contato interétnico vivida por cada povo...”. É nesse sentido que os povos indígenas reivindicam atenção especial à saúde dos povos, dado as singularidades e especificidades de cada um.

A VI Conferência Nacional de Saúde indígena está marcada para $1^{\circ}$ a $4^{\circ}$ de Julho de 2020, logo depois do MUTIRÃO na Aldeia Pará Pataxó. Nela se pretende atualizar o modelo de atenção à Saúde dos Povos Indígenas. Espera-se reunir mais de 2000 pessoas entre indígenas e trabalhadores da Saúde Indígena. Essa Conferência será importantíssima na definição das diretrizes futuras para os povos

16 Idem. 
indígenas do Brasil e a tentativa de preservar as conquistas feitas nos últimos 20 anos por esses povos. Sua ideia é não declinar e não perder direitos, mas exigir e determinar o melhoramento das suas condições de saúde. Mediante as atuais perseguições às lideranças indígenas e as perdas constantes de direitos, essa Conferência Nacional apresenta-se como uma grande manifestação política.

\section{Futuro}

É justamente o poder e a potência de justiça que vem da inspiração em Marielle Franco que ainda nos impulsiona a continuar apoiando projetos como o Centro de Saúde Pataxó, como também o apoio total e irrestrito ao Movimento dos Trabalhadores Rurais Sem Terra.

Caminhada que completa um ano de comitê Marielle Franco. O que posso confessar é que o trabalho político, quando sincero e real, é um percurso cheio de dúvidas, com uma constante renovação dos afetos que sincretizam o público, sério e concentrado, com o doméstico, irreverente, que procura a alegria e o bem-viver. Como Marielle, se assim posso arriscar, pensava que na política estamos, porque somos do momento que acordamos ao momento que vamos dormir, animais políticos.

Repito a palavra porque o desafio pode parecer difícil, de dialogar com frentes distintas e por vezes críticas umas às outras, por vezes com objetivos mesmos bem mais distintos do que desejaríamos. Uma sabedoria que é, sabendo que somos todos diferentes e que reagir, no entanto, é preciso. Talvez pensar como um trabalho numa escala menor dê, não somente menos medo, mas também uma segurança de que o que estamos fazendo é real e possível. Uma coisa é certa : não conseguiríamos atingir tamanho alcance do comitê sem a confiança e a ajuda de todos os participantes.

Nisso segue as lições de Paulo Freire e bell hooks, o ativismo é afetivo, porque é pedagógico e emancipador, mesmo que num instante de um evento, publicação ou abraço. Cheio de amor e carinho.

Marielle, présente ! 
Relato sobre a experiência do comitê Marielle Franco de

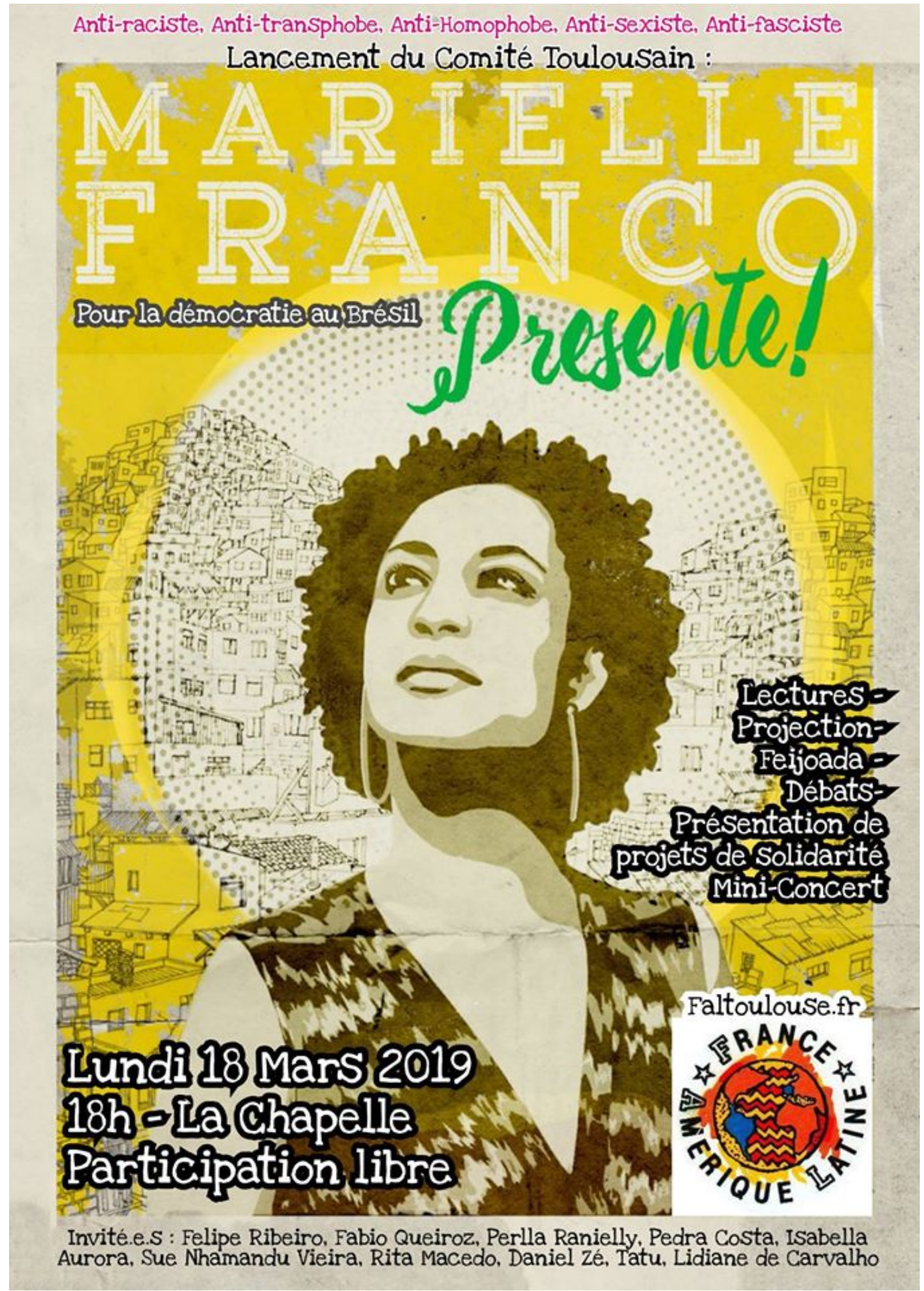

Fig. 6 Cartaz da festa de lançamento do comitê Marielle Franco de Toulouse. Design : Julien Oziel. 


\section{Rapport sur l'expérience du comité Marielle Franco de Toulouse}

RÉSUMÉ: Un essai qui cherche à résumer les actions et le parcours du comité Marielle Franco de Toulouse, ainsi qu'un témoignage personnel et affectif, la proposition de l'essai est de mettre en lumière un savoirfaire à organiser des événements qui rassemblent l'aide aux mouvements sociaux au Brésil, d'une lutte en exil et de l'immigration en Europe. Il s'agit donc d'un dialogue d'intensités et de courage, visant ainsi une poétique de la vie, et non seulement une politique.

MoTS-CLÉs: Marielle Franco. Toulouse. France.

Raisa Inocencio Ferreira LIMA

Filosofia e performance com foco no ativismo político e de gênero, participante da rede Tecnoxamanismo e do comitê Marielle Franco de Toulouse.

Recebido em: $31 / 12 / 2019$

Aprovado em: 12/10/2020 